\title{
OM-85 BV, an immunostimulant in pediatric recurrent respiratory tract infections: a systematic review
}

\author{
Urs B Schaad \\ Basel, Switzerland
}

Background: This study was conducted to assess the efficacy of OM-85 BV (Broncho-Vaxom) in the prevention of pediatric recurrent respiratory tract infections (RTIs). Available evidence suggests that defining recurrent RTIs as $\geq \mathbf{3}$ infections per fall-winter semester is both medically and epidemiologically justified. Therefore, this criterion was chosen as a primary endpoint.

Methods: Trials were identified through consultation of bibliographic databases and other channels. Eleven non-blinded studies plus one dealing with primary prevention were excluded and eight randomized controlled trials were included in the meta-analysis. The data were compared at 6 months, which represented the end of most studies. The complete database was examined according to the guidelines of the Cochrane collaboration.

Results: The mean age of children and the number of RTIs in the preceding year were comparable at admission. Of the patients in the OM-85 BV treated population $(n=435), 32 \%$ had recurrent RTIs (that is, $\geq 3$ RTIs/6 months) vs. $58.2 \%$ in the placebo treated population $(n=416 ; P<0.001)$. Sensitivity analysis showed that this was not driven by any particular trial. The results of this review were also positive for the active treatment regarding the secondary variables, which were represented by the number of patients with at least one RTI and the mean number of RTIs.

Conclusions: This meta-analysis shows, as observed in several individual trials, that the population treated with OM-85 BV had significantly and consistently fewer cases of recurrent RTIs. The data suggest that the effect is greater in patients at increased risk of recurrent RTIs.

World J Pediatr 2010;6(1):5-12

Author Affiliations: Division of Pediatric Infectious Diseases, University Children's Hospital, Basel, Switzerland (Schaad UB)

Corresponding Author: Urs B Schaad, MD, Division of Pediatric Infectious Diseases, University Children's Hospital Basel (UKBB), Römergasse 8, CH-4005 Basel, Switzerland (Tel: +41 6168562 56; Fax: +416168560 01; Email: urs-b.schaad@unibas.ch)

doi:10.1007/s12519-010-0001-x

(C)2010, World J Pediatr. All rights reserved.
Key words: children;

immunostimulant;

OM-85 Broncho-Vaxom;

recurrent respiratory tract infections

\section{Introduction}

$\mathrm{O}$ M-85 BV (Broncho-Vaxom) is an immunostimulant medication used to prevent recurrent respiratory tract infections (RTIs). The mechanism of its action has recently been reviewed by Rozy et al. ${ }^{[1]} \mathrm{OM}-85 \mathrm{BV}$ has been shown to induce the terminal maturation of human dendritic cells, with an enhanced $\mathrm{T}$ cell-stimulatory capacity in vitro. ${ }^{[2]}$ The broncho-alveolar lavage of adults treated with OM-85 $\mathrm{BV}^{[3,4]}$ showed an increase in the helper/suppressor $\mathrm{T}$ lymphocyte ratio, a stimulation of the impaired alveolar macrophage activity, and increased concentrations of interferon- $\gamma$.

The clinical aspects of recurrent pediatric RTIs have been dealt with in detail in a recent systematic review, ${ }^{[5]}$ including pathogenesis, prevention and "key" trials with OM-85 BV. Therefore, the paper presented herein shall concentrate on a meta-analytic approach, attempting to quantify the effectiveness of OM-85 in the secondary prevention of recurrent RTIs in children.

It is widely accepted that recurrent RTIs in childhood represent a problem per se in addition to increasing predisposition to future respiratory problems. Repeated lower RTIs in the first 3 years of life show a positive association with wheezing up to the age of 7 years. ${ }^{[6]}$ However, the concept of recurrence in relation with RTIs presents some problems since there is no generally agreed definition. Preschool children may contract between four and six RTIs over the course of a year without this representing a true deviation from "normality". ${ }^{[7]}$ In a German study it was shown ${ }^{[8]}$ that the number of febrile episodes in the first year of life was superior to three in about $28 \%$ of the infants and that about $9 \%$ had two or more courses of antibiotics. Several episodes seem "normal" since several peaks of exposure to different agents occur during each season. ${ }^{[9]}$ Some authors ${ }^{[10]}$ 
have attempted to define recurrence of infection by clinical presentation, e.g., three episodes of otitis over 6 months or two episodes of sinusitis and/or recurrent bronchopneumonia in 6 months or four episodes of rhinopharyngitis in 6 months. Such a classification, particularly in younger children, however seems somewhat artificial. Therefore, epidemiological and clinical observations favor the concept that the term "recurrent" should be reserved for cases of several RTIs per fall-winter season, e.g., three or more. ${ }^{[5,11]}$

Several factors such as day care in local nursery and short duration of breastfeeding predispose to recurrent RTIs, particularly otitis media, as well as to wheezy bronchitis ${ }^{[12]}$ and should therefore be considered as covariates in clinical studies.

In addition to being the most frequent causative agents of respiratory disease, viral infections can predispose to bacterial superinfection. The proportion of children with mixed viral and bacterial RTIs found in studies using serology or antigen detection in serum or urine has been reported to be as high as $40 \%$. However, these methods may be inadequate for assessing the clinical importance of bacterial infection or the need for antimicrobial treatment. ${ }^{[13]}$

In order to provide a more accurate quantitative estimate of the overall treatment effects of a frequently employed immunostimulant, we performed a metaanalysis of studies in children with a history of recurrent RTIs. As in adults ${ }^{[14]}$ limiting the assessment to the proportion of children without any RTI after treatment with an immunostimulant may provide a biased picture, so the cut-off was therefore set at 3 or more RTIs over 6 months.

\section{Methods \\ Objective}

The primary objective of this meta-analysis was to provide a more accurate estimate of the overall treatment effects of OM-85 BV from a clinical point of view, choosing clinically relevant end points as described in the study by Schaad et al. ${ }^{[11]}$ The cut-off for the outcomes was set at 6 months; the following criteria were defined a priori (RTI as defined in each study protocol):

1) Primary endpoint: proportion of patients with recurrent RTIs (that is $\geq 3$ RTIs per 6 months);

2) Secondary endpoints: proportion of patients with at least one RTI and mean number of RTIs during 6 months.

No distinction was made between the different clinical diagnoses of RTIs. Since the frequency of RTIs decreases with the age of children and since the number of RTIs in the current season correlates with the number of events in the preceding year, ${ }^{[11,15]}$ examination of these two variables as a control of comparability of the patient populations at admission to the trial was decided upon. The guidelines provided by the Cochrane Collaboration Handbook for Reviews ${ }^{16]}$ have been applied in the analysis of the clinical data.

\section{Search strategy}

The data sources for the identification of trials included bibliographic databases (TOXLINE, MEDLINE, HealthSTAR, AIDSLINE and CANCERLIT, Embase, AMED, Cochrane Library, PudMed (/www.ncbi.nlm. nih.gov), TOXMAP, TOXLINE Special, DART Special, HSDB, IRIS, ITER, GENETOX, CHEMIDplus, HazMap), hand-searching reference lists from pertinent review articles and books, and personal contacts with experts active in the area and manufacturers up to April 2009. Full disclosure of the product documentation including requested statistical and official reports by the manufacturer in Switzerland warranted a minimal publication bias. All papers were screened, and any dealing with prospective clinical trials were retained for classification according to the selection criteria described below. In case of double publications, the authors retained those which were most recent and/or had been published in a peer-reviewed journal.

All trials eligible were summarized in a tabulated format. The standard table included a full reference, a quality rating, the type of pathology, demographic data and treatments, end-points and adverse events. The trials dealing with pediatric respiratory tract infections were retained.

\section{Material scrutinized}

The electronic databases identified recurrent infections, OM-85, Broncho-Vaxom, Imocur, placebo, doubleblind and infants (age, 1-23 months) / children (age, 2-12 years) in 22 publications. Two additional publications of clinical studies were identified through other channels as mentioned above, and duly scrutinized.

Five studies were descriptive, open-labelled pediatric studies and one was a cost-effectiveness model analysis; these had to be discarded. Ten comparative studies were excluded as they did not comply with one or more criteria (Table 1). ${ }^{[17-26]}$ Eight studies were retained as relevant trials dealing with secondary prevention, and were retained for closer examination (Table 2).$^{[1,27-33]}$ Four of these trials were conducted in Western Europe and the remaining four in Mexico: they were all totally or partially industry-sponsored.

\section{Selection criteria}

Initially, all articles, published and unpublished trials, were considered for review. They were subsequently 
classified by study design, screened and weighted, based on their methodological quality (methods, participants, interventions, outcome measures and results). Quality assessment was based on a rating of the trials by the criteria published by Jadad et al..$^{[34]}$

Eleven studies were excluded as they were nonblinded or incomplete. Nine studies were retained as relevant trials and, finally, eight dealing with secondary prevention were included in the meta-analysis (Table 2). ${ }^{[1,27-33]}$ All trials only admitted children with a documented history of recurrent RTIs.

Regarding similarities and differences in the trials selected, the study of Schaad et al ${ }^{[11]}$ required the patients to actually have an episode of RTI at admission, while all the other studies only admitted children with a documented history of recurrent RTIs. The patients studied by Gomez-Barreto et $\mathrm{al}^{[28]}$ had sinusitis, and those reported by Zagar and LöflerBadzek $^{[33]}$ had chronic rhinosinusitis. The trial of JaraPerez and Berber ${ }^{[30]}$ included only girls living in an orphanage, and the trial of Del-Rio-Navarro et al ${ }^{[27]}$ included children with subnormal serum IgG. JaraPerez and Berber ${ }^{[30]}$ and Schaad et al ${ }^{[32]}$ provided clinical descriptions of the RTIs which are not discussed herein.
The dosing schedules used in the trials included in this meta-analysis are shown in Table 3.

\section{Statistical analysis}

Data were extracted from the pertinent publications and/or study reports in order to obtain for each of the selected trials the key variables defined as endpoints and the demographic data deemed of interest as set forth in the trial by Schaad et al ${ }^{[11]}$ (age of the patient and number of RTIs over the preceding 12 months, number of patients completing trial). These data were checked for consistency and adequacy of tests employed. Missing data were reconstructed through iterative procedures. The completed database was entered in Review Manager 2.4.7 software of the Cochrane collaboration; binary data were examined by the Peto-Mantel-Haenszel test. ${ }^{[35]}$ Whenever the authors specified two sets of data, the intent to treat analysis was chosen. The denominator ' $\mathrm{N}$ ' indicated the number of patients reported by the authors; if not specified, ' $\mathrm{N}$ ' was the number of patients who were admitted to the trial. Sensitivity analysis was made by sequential elimination of trials and by elimination of outlier trials, with an outlier being defined as "an extreme value that

Table 1. Summary of comparative trials screened and excluded (alphabetically)

\begin{tabular}{|c|c|c|c|c|c|}
\hline Author (year) & Recurrent RTIs? & Double blind? & Placebo? & Age 1-12 y? & Reasons for exclusion \\
\hline Ahrens (1984) & Yes & Yes? & Yes & No & $\begin{array}{l}\text { Not adequate blinding, age not as } \\
\text { defined }\end{array}$ \\
\hline Chen (2007) & Wheezing & No & budesonide & Yes & $\begin{array}{l}\text { Indication, not adequate blinding, } \\
\text { no placebo }\end{array}$ \\
\hline Collet (1993) & Primary prevention & Yes & Yes & Yes & Indication \\
\hline Field (1998) & Primary prevention & No & vs. previous year & Yes & Indication, no blinding, no placebo \\
\hline Gutiérrez-Tarango (1997) & Yes & No & Conventional treatment & Yes & No blinding, no placebo \\
\hline Kapellerova (1989) & Yes & No & "Bacterial vaccine" & Yes & No blinding, no placebo \\
\hline Maestroni (1984) & Predisposition & Yes? & Yes & No & $\begin{array}{l}\text { Indication, not adequate blinding, } \\
\text { age not as defined }\end{array}$ \\
\hline Martin du Pan (1982) & No & No & Yes & Yes & Indication, not adequate blinding \\
\hline Quezada (1999) & Yes + hypogammaglobulinemia & No & Yes & Yes & Indication, not adequate blinding \\
\hline Ziuzio (1994) & Allergy & No & Polyvaccium; IRS-19 & Yes & Indication, no blinding, no placebo \\
\hline
\end{tabular}

Table 2. Summary of trials screened and selected rating by Jadad criteria

\begin{tabular}{|c|c|c|c|c|c|c|c|c|c|}
\hline \multirow[t]{3}{*}{ Jadad criteria } & \multicolumn{9}{|c|}{ Prevention } \\
\hline & \multicolumn{8}{|c|}{ Secondary } & \multirow{2}{*}{$\begin{array}{l}\text { Primary } \\
\text { Collet } \\
\text { (1993) }\end{array}$} \\
\hline & $\begin{array}{r}\text { Del-Rio } \\
(2003)\end{array}$ & $\begin{array}{l}\text { Schaad } \\
(2002)\end{array}$ & $\begin{array}{l}\text { Gutierrez-T. } \\
(2001)^{*}\end{array}$ & $\begin{array}{c}\text { Jara-Perez } \\
(2000)\end{array}$ & $\begin{array}{c}\text { G.-Barreto } \\
(1998)^{\dagger}\end{array}$ & $\begin{array}{l}\text { Paupe } \\
(1990)\end{array}$ & $\begin{array}{l}\text { Zagar } \\
\text { (1988) }\end{array}$ & $\begin{array}{r}\text { Schaad } \\
(1986)\end{array}$ & \\
\hline Is the study randomized? & $\mathrm{Y}$ & $\mathrm{Y}$ & Y & $\mathrm{Y}$ & $\mathrm{Y}$ & $\mathrm{Y}$ & $\mathrm{Y}$ & $\mathrm{Y}$ & $\mathrm{Y}$ \\
\hline Is the study double-blinded? & $\mathrm{Y}$ & $\mathrm{Y}$ & Y & $\mathrm{Y}$ & $\mathrm{Y}$ & $\mathrm{Y}$ & $\mathrm{Y}$ & $\mathrm{Y}$ & $\mathrm{Y}$ \\
\hline Is there a description of withdrawals? & $\mathrm{Y}$ & $\mathrm{Y}$ & Y & $\mathrm{Y}$ & $\mathrm{Y}$ & $\mathrm{Y}$ & $\mathrm{Y}$ & $\mathrm{Y}$ & $\mathrm{Y}$ \\
\hline Is the randomization adequately described? & $\mathrm{P}$ & $\mathrm{Y}$ & $P$ & $\mathrm{P}$ & $P$ & $\mathrm{P}$ & No & $\mathrm{P}$ & $\mathrm{Y}$ \\
\hline Is the blindness adequately described? & $\mathrm{P}$ & $\mathrm{Y}$ & $\mathrm{P}$ & $P$ & $\mathrm{P}$ & $\mathrm{Y}$ & No & $\mathrm{P}$ & $\mathrm{Y}$ \\
\hline Score & 4 & 5 & 4 & 4 & 4 & 4.5 & 3 & 4 & 5 \\
\hline
\end{tabular}

Y (yes): 1 point; P (partial): 0.5 points; No: 0 point. *: 12 months trial; the values at 6 months were considered for the current analysis. $\dagger:$ after sinusitis. 
might have a low probability of occurrence but cannot be statistically shown to originate from a different distribution than the rest of the data". ${ }^{[36]}$ Additional and exploratory analyses were made employing the WinSTAT $^{\mathrm{TM}}$ for Excel Version 2001.1.

\section{Results}

\section{Key demographic data, comparability at baseline}

As described in the Methods section, since the age of the children and the number of RTIs in the preceding year are correlated with the number of RTIs to be expected during the trial, these two variables were regarded as a control of comparability of the patient populations at admission to the trial.

The mean number of RTIs in the previous year was similar in the two populations (mean of studies with the information: $6.12 \pm 3.74$ RTIs in the OM- 85 BV populations vs. $6.23 \pm 3.52$ RTIs in the placebo), but no such information was available in the study by Gomez-Barreto ${ }^{[28]}$ while the study by Paupe ${ }^{[31]}$ provided some other relevant information about the similarity between therapeutic groups. With these caveats, the patient population can be accepted as homogeneous.
The number of drop-outs is comparatively small in both therapeutic groups; in the majority of the cases, patients dropped out because of administrative reasons.

In Table 4 the mean ages at admission (pooled mean \& SD) and the number of patients are depicted, whereas Table 5 shows the mean number of RTIs in the previous year.

\section{Proportion of patients with RTIs}

Although the data were heterogeneous, $32 \%$ of the patients within the OM-85 BV treated population had recurrent RTIs ( $\geq 3$ RTIs per 6 months), vs. $58.2 \%$ of the placebo treated population, indicating that the active treatment led to $26.2 \%$ fewer patients with recurrent RTIs (Fig. 1). The large proportion of placebo patients without recurrent RTIs is probably best explained by the natural trend of children to suffer from fewer RTIs as they grow older.

Sensitivity analysis by sequential elimination of trials yielded odds ratios between 0.42 and 0.6 , and significance level unchanged at $P<0.001$. After elimination of the outlier trials by Jara-Perez, ${ }^{[30]}$ which showed the largest difference between treatments, and by Schaad, ${ }^{[32]}$ which tilted towards placebo, the database became homogeneous, showing that there

Table 3. Dosing schedules employed in examined trials

\begin{tabular}{|c|c|c|c|c|c|c|c|c|c|c|c|c|}
\hline \multirow{2}{*}{$\begin{array}{l}\text { Author (year) } \\
\text { Del-Rio (2003) }\end{array}$} & mon 1 & mon 2 & mon 3 & mon 4 & mon 5 & \multirow[t]{2}{*}{ mon 6} & \multirow[t]{2}{*}{ mon 7} & mon 8 & \multirow[t]{2}{*}{ mon 9} & \multirow[t]{2}{*}{ mon 10} & \multirow[t]{2}{*}{ mon 11} & \multirow[t]{2}{*}{ mon 12} \\
\hline & & & & & & & & & & & & \\
\hline Schaad (2002) & & & & & & & & & & & & \\
\hline Gutierrez-Tara & & & & & & & & & & & & \\
\hline Jara-Perez (200 & & & & & & & & & & & & \\
\hline Gomez-Barretc & & & & & & & & & & & & \\
\hline Paupe (1990) & & & & & & & & & & & & \\
\hline Zagar (1988) & & & & & & & & & & & & \\
\hline Schaad (1986) & & & & & & & & & & & & \\
\hline Cut-off & & & & & & $\rightarrow$ & $\leftarrow$ & & & & & \\
\hline Collet (1993) & & & & & & & & Primar & prevent & n; Exclud & & \\
\hline
\end{tabular}

Gray areas: one capsule OM-85 BV in the morning. One capsule OM-85 BV for children contains $3.5 \mathrm{mg}$ of lyophilized bacterial lysates of Haemophilus influenzae, Diplococcus pneumoniae, Klebsiella pneumoniae and ozaenae, Staphylococcus aureus, Streptococcus pyogenes and viridans, Neisseria catarrhalis.

Table 4. Mean ages at admission (pooled mean \& SD) and number of patients

\begin{tabular}{|c|c|c|c|c|c|c|c|c|}
\hline \multirow[t]{2}{*}{ Author (year) } & \multicolumn{2}{|c|}{ Age (y) OM-85-BV } & \multicolumn{2}{|c|}{ Age (y) placebo } & \multicolumn{2}{|c|}{$\mathrm{N}$ patients $\mathrm{OM}-85-\mathrm{BV}$} & \multicolumn{2}{|c|}{$\mathrm{N}$ patients placebo } \\
\hline & Mean & $\mathrm{SD}$ & Mean & $\mathrm{SD}$ & Intent to treat & Completed & Intent to treat & Completed \\
\hline Schaad (2002) & 5.19 & 1.42 & 5.27 & 1.37 & 120 & 98 & 100 & 85 \\
\hline Gutierrez-Tarango (2001) & 3.86 & 2.44 & 4.52 & 2.70 & 26 & 26 & 28 & 27 \\
\hline Del Rio (2003) & 4.00 & 0.90 & 4.10 & 0.90 & 25 & 22 & 24 & 21 \\
\hline Jara-Perez (2000) & 9.76 & 1.89 & 9.62 & 1.88 & 100 & 99 & 100 & 100 \\
\hline Gomez-Barreto (1998) & 4.69 & 1.72 & 4.06 & 1.81 & 26 & 26 & 30 & 30 \\
\hline Paupe (1991) & 6.60 & 5.30 & 7.60 & 5.30 & 64 & 61 & 63 & 55 \\
\hline Zagar (1988) & 6.53 & 5.08 & 6.81 & 4.50 & 29 & 29 & 22 & 22 \\
\hline Schaad (1986) & 4.33 & 2.79 & 4.09 & 2.49 & 45 & 45 & 49 & 49 \\
\hline Pooled mean \& SD & 6.27 & 3.60 & 6.41 & 3.57 & 435 & 406 & 416 & 389 \\
\hline Completed $(\%)$ & & & & & & $93.3 \%$ & & $93.5 \%$ \\
\hline
\end{tabular}


were $20.2 \%$ fewer patients with recurrent RTIs within the remaining OM-85 BV treated population than in the placebo treated population.

By the observations of individual trials, one may conclude that the population treated with OM-85 BV had significantly and consistently fewer patients with recurrent RTIs ( $\geq 3$ RTIs per 6 months) by between $26.2 \%$ and $20.2 \%$ (the latter as a conservative estimate after obtaining a homogeneous database by eliminating the outlying trials). Likewise and as expected, there is also a significant reduction in the relative risk (RR (fixed) \& 95\% CI: $0.56[0.48,0.66])$ and in the odds ratio (OR (fixed) \& 95\% CI: 0.33 [0.25, 0.45]).

In both treatment groups, the majority of children had at least one RTI during the study period (Table 6). Although the data were somewhat heterogeneous, over $16.2 \%$ of patients had no RTI in the period under consideration within the OM-85 BV treated population (27.3\% with OM-85 BV vs. $11.1 \%$ with placebo). Likewise, there was also a significant reduction in the odds ratio (OR OM-85 BV: placebo was 0.33 [95\% CI: $0.23,0.49])$. Sensitivity analysis by sequential elimination of trials yielded odds ratios between 0.38 and 0.52 , significance level unchanged at $P<0.001$.

Table 5. Mean N RTIs in the previous year

\begin{tabular}{lccccc}
\hline N RTIs previous year & \multicolumn{2}{c}{ OM-85 BV } & & Placebo \\
\cline { 2 - 3 } \cline { 5 - 6 } & Mean & SD & & Mean & SD \\
\hline Schaad et al (2002) & 5.76 & 2.38 & & 6.06 & 2.13 \\
Gutierrez-Tarango (2001) & 12.62 & 4.82 & & 12.32 & 3.85 \\
Del Rio (2003) & 9.40 & 3.70 & & 10.10 & 2.80 \\
Jara-Perez (2000) & 4.94 & 0.76 & & 5.09 & 0.70 \\
Gomez-Barreto (1998) & No data & & & No data \\
Paupe (1991) & N RTIs $>4: 54 \%$ & & N RTIs $>4: 58 \%$ \\
Zagar (1988) & 6.72 & 6.40 & & 5.59 & 6.46 \\
Schaad (1986) & 3.76 & 1.86 & & 3.82 & 1.82
\end{tabular}

The trials therefore indicated that the population treated with OM-85 BV had significantly and consistently fewer patients with one or more RTIs in a 6-month period (Table 6). Moreover, after elimination of the largest favorable "outlier", i.e., the trial of DelRio-Navarro ${ }^{[27]}$ in children with $\operatorname{IgG}$ deficiencies, and the worst trial outcome for this variable ${ }^{[11]}$ this figure was $17.0 \%$, which was even more significant.

\section{Mean number of RTIs in 6 months}

The analysis of the mean number of RTIs over 6 months had to be regarded with some caution since the data were actually ordinal (that is, natural whole numbers) and not all trials were suitable for such an analysis because of differences in variances. Nevertheless, the mean number of RTIs was significantly lower in the OM-85 BV treated population, by an average of -1.15 (95\% CI: $-1.55,-0.75)$ RTIs/6 months (Table 7). After eliminating the outlier studies for this variable (i.e.,

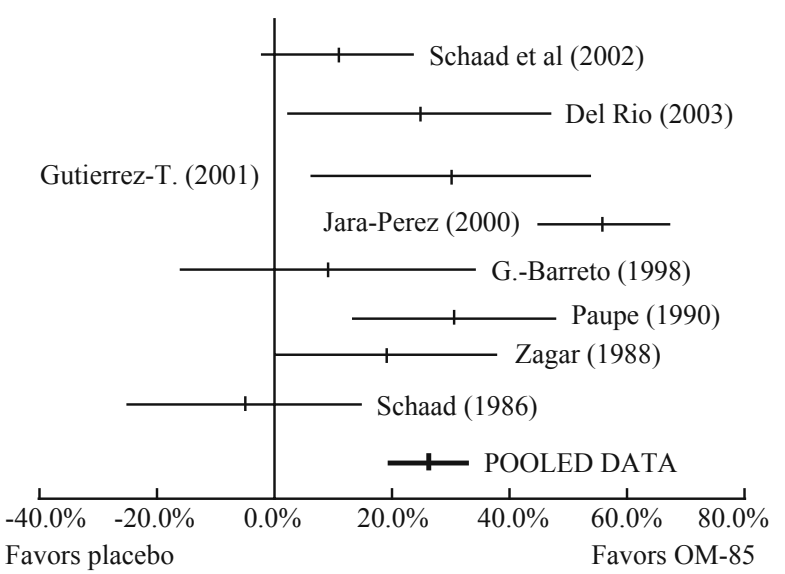

Fig. 1. Percent difference (and $95 \%$ confidence interval) between treatments for patients with recurrent RTIs ( $\geq 3$ RTIs/6 months).

Table 6. Number of patients with RTIs ( $\geq 1$ or $\geq 3$ RTIs/6 months), per trial \& treatment

\begin{tabular}{|c|c|c|c|c|}
\hline \multirow[t]{2}{*}{ Author (year) } & \multicolumn{2}{|c|}{1 or more RTIs } & \multicolumn{2}{|c|}{3 or more RTIs } \\
\hline & OM-85-BV & Placebo & OM-85-BV & Placebo \\
\hline Schaad et al (2002) & $103(85.8 \%)$ & $87(87 \%)$ & $39(32.5 \%)$ & $44(44 \%)$ \\
\hline Gutierrez-Tarango (2001) & $23(85.2 \%)$ & $28(100 \%)$ & $14(51.9 \%)$ & $23(82.1 \%)$ \\
\hline Jara-Perez (2000) & $86(86 \%)$ & $100(100 \%)$ & $14(14 \%)$ & $70(70 \%)$ \\
\hline Del Rio (2003) & $2(10 \%)$ & $20(100 \%)$ & $14(70 \%)$ & $19(95 \%)$ \\
\hline Paupe (1990) & $37(60.7 \%)$ & $46(83.6 \%)$ & $19(31.1 \%)$ & $34(61.8 \%)$ \\
\hline Zagar (1988) & $8(27.6 \%)$ & $9(40.9 \%)$ & $1(3.4 \%)$ & $5(22.7 \%)$ \\
\hline Schaad (1986) & $39(86.7 \%)$ & $48(98 \%)$ & $28(62.2 \%)$ & $28(57.1 \%)$ \\
\hline Gomez-Barreto (1998) & $13(50 \%)$ & $21(70 \%)$ & $8(30.8 \%)$ & $12(40 \%)$ \\
\hline Pooled (significance: $P<0.001)^{*}$ & $311(72.7 \%)$ & $359(88.9 \%)$ & $137(32 \%)$ & $235(58.2 \%)$ \\
\hline Number needed to treat & 6.2 & & 3.8 & \\
\hline Odds ratios OM-85-BV: placebo & $0.33(95 \% \mathrm{CI}$ & & $0.33(95 \% \mathrm{CI}$ & \\
\hline \multicolumn{5}{|c|}{ "Robust analysis" after deleting Jara-Perez (2000) as positive 'outlier' \& Schaad (1986) as negative 'outlier': } \\
\hline Pooled (significance: $P<0.001$ ) & $186(65.7 \%)^{*}$ & $211(82.7 \%)$ & $95(33.6 \%)^{\dagger}$ & $137(53.7 \%)$ \\
\hline
\end{tabular}

*: Test for heterogeneity: $P=0.001$ for 1 or more RTIs, $P<0.00001$ for 3 or more RTIs; $\uparrow$ : Test for heterogeneity: $P>0.1$. 
Gutierrez-Tarango ${ }^{[29]} \&$ Schaad $^{[32]}$ ) the mean number of RTIs continued to be significantly lower in the OM-85 $\mathrm{BV}$ treated population, by an average of -1.10 (95\% CI: $-1.64,-0.56)$ RTIs/6 months.

The weighted mean difference (WMD; also defined as "effect size") between mean numbers of RTIs over 6 months was -1.21 [95\% CI: $-1.39,-1.03]$ in favor of the active treatment $(P<0.00001)$, although the test for heterogeneity was also highly significant. This heterogeneity was probably due to the differences in age of patients and in the number of RTIs in the preceding year.

Several co-variates were likely to influence the outcomes and might explain the heterogeneity found in some variables. They were briefly illustrated, although they had not been submitted to a formal analysis. The mean number of RTIs was consistent with the number of RTIs in the preceding year and with the age of the patients (Fig. 2). Namely, the number of RTIs in the preceding year appeared to have a major bearing on the results, the benefit of OM-85 BV was markedly greater in children with a history of very frequent RTIs (confirmed by multiple stepwise regression analysis in a subset of trials with raw data available, data not shown).

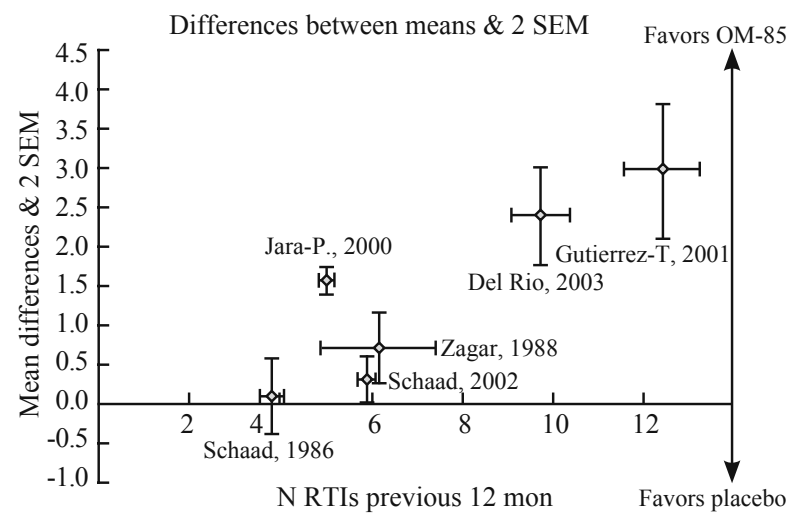

Fig. 2. Differences (and 95\% confidence interval) between treatments, mean number of RTIs by N RTIs in the year before admission.
The quality assessment of the studies, i.e., the Jadad rating system, had no evident influence on the outcomes. The funnel plots, which should be regarded as a generic instrument for examining small study effects rather than a tool to diagnose specific types of bias, did not suggest the existence of publication or any other major bias in this meta-analysis.

\section{Safety}

The incidence of minor adverse events in the clinical trials was $17.7 \%$ for the OM- $85 \mathrm{BV}$ treated and $18.2 \%$ for the placebo treated patients; the majority of adverse events were gastrointestinal or cutaneous findings. Serious adverse events were reported in $1 \%$ vs. $0.5 \%$, withdrawals due to adverse event in $1.3 \%$ vs. $0.7 \%$, respectively. No causal relationship has been established for any of these adverse events. No laboratory abnormalities in relation with OM-85 BV have been reported in the literature. There were neither deaths nor serious adverse events attributed or possibly attributable to the study medication.

\section{Discussion}

Steurer-Stey et $\mathrm{al}^{[37]}$ used a partially meta-analytical approach of published data with OM-85 BV; their findings, however, remained fragmentary due to failure to request additional information from the manufacturer or other sources. Moreover, their report also analyzed other bacterial immunostimulants. They concluded that their "systematic review provides weak evidence that oral immunostimulation with bacterial extracts prevents acute RTIs in children." There was a trend for fewer infections over 6 months of follow-up in children not in day care as well as a small reduction in number of antibiotic courses.

Our study showed that with the active treatment there were $26.2 \%$ fewer patients with recurrent RTIs

Table 7. Mean number of RTIs in 6 months (pooled mean \& SD) by treatment

\begin{tabular}{|c|c|c|c|c|c|}
\hline \multirow[t]{2}{*}{ N RTIs/6 months } & \multicolumn{2}{|c|}{ OM-85 BV } & \multicolumn{2}{|c|}{ Placebo } & \multirow[t]{2}{*}{ Comments } \\
\hline & Mean & SD & Mean & SD & \\
\hline Schaad et al (2002) & 2.12 & 1.44 & 2.48 & 1.63 & \multirow{5}{*}{ Variances, ${ }^{*} P=0.06$} \\
\hline Gutierrez-Tarango (2001) & 5.04 & 1.95 & 8.00 & 2.51 & \\
\hline Del Rio (2003) & 2.80 & 1.40 & 5.20 & 1.50 & \\
\hline Jara-Perez (2000) & 1.43 & 0.94 & 2.99 & 0.81 & \\
\hline G.-Barreto (1998) & 1.56 & 1.53 & 2.22 & 2.43 & \\
\hline Paupe (1991) & 2.07 & 2.09 & 3.51 & 2.97 & $\mathrm{SD}_{\text {estimated }}{ }^{\dagger}$ \\
\hline Zagar (1988) & 0.38 & 0.71 & 1.09 & 1.50 & Variances, ${ }^{*} P=0.003$ \\
\hline Schaad (1986) & 2.89 & 1.77 & 2.98 & 1.56 & \\
\hline Pooled mean \& SD & 2.09 & 1.79 & 3.24 & 2.40 & $P<0.001$ \\
\hline \multicolumn{6}{|c|}{ Pooled mean \& SD after eliminating 'outlier' trials of Gutierrez-Tarango (2001) \& Schaad (1986) } \\
\hline Pooled mean \& SD & 1.78 & 2.51 & 2.88 & 4.21 & $P<0.001$ \\
\hline
\end{tabular}

*: Bartlett-Test for homogeneity of variances; $\uparrow:$ SD estimated to be equal to average ratio SD/mean of the other trials. 
(i.e., $\geq 3 \mathrm{RTI} / 6$ months). The fact that the population of the different trials included in the meta-analysis is homogeneous (after excluding the two 'outliers') in terms of this variable lends strength to the highly significant results in favor of OM-85 BV.

The proportion of patients with any RTI (i.e., $\geq 1$ RTI/6 months) was reduced by $16.2 \%$ in our study, but this variable is of lesser clinical relevance in view of the multiple agents which can cause acute symptoms of an RTI during one single season, probably involving different defence mechanisms. Sensitivity analysis was made for all variables and no particular trial driving the efficacy outcomes was identified, thus corroborating the results. In line with similar analyses ${ }^{[38,39]}$ the mean number of RTIs was reduced by $35.5 \%$ but the data, although a highly significant difference was found in favor of OM-85 $\mathrm{BV}$, are very heterogeneous. The heterogeneity in the secondary outcomes is probably explained by clinical and methodological diversity, dependent on the age, the risk of RTIs (as N RTIs in the preceding year) and other variables. For example, the 'outlier' study of Jara-Pere $z^{[30]}$ had several particular characteristics as it was conducted under the very controlled conditions of an orphanage for girls.

Exploratory analysis indicates that efficacy is more pronounced in patients at high risk of recurrent RTIs; the benefit of OM-85 BV as compared to placebo was notoriously greater in children with a history of very frequent RTIs.

The influence of industry-sponsoring on the outcomes of trials has been discussed controversially; that is, no influence was found in some cases ${ }^{[40]}$ while in others the results tipped in favor of the sponsored drug. ${ }^{[4]]}$ Metaanalysis sponsored by industry came to more "drugfriendly" conclusions than independent studies, even if the estimated treatment effect was similar. ${ }^{[42]}$

The positive and negative predictive value of metaanalysis should be taken into consideration. Agreement between meta-analyses and large clinical trials of therapeutic interventions can be expected in $68 \%$ of the cases, while a statistically significant difference was found in only $12 \%$ of the cases; in no case, however, there was a divergence in which the randomized clinical trial and the meta-analysis yielded statistically significant and opposite results. ${ }^{[43]}$ It is important to note that the outcomes concerning the primary variable were homogeneous in robust analysis since heterogeneity in the outcomes of individual trials appears to be an important predictor of discrepancy between metaanalyses and large clinical trials. ${ }^{[4]}$

We believe that this analysis may help both the practitioner in identifying the best candidates for this immunostimulant therapy and the investigators in setting up new randomized controlled trials in this complex field. Future studies should provide details of the RTIs occurring during the observation period employing a standardized clinical classification.

\section{Acknowledgements}

The author is thankful to Dr. Reto G. Brignoli for assistance with the statistical analysis and preparation of the manuscript.

Funding: This project was partially funded by OM Pharma, Geneva, Switzerland. The sponsors had no involvement in the study design, analysis and interpretation of the data, writing of the manuscript, or in the decision to submit the manuscript for publication.

Ethical approval: Not needed.

Competing interest: None.

Contributors: Schaad UB is the single author of this paper.

\section{References}

1 Rozy A, Chorostowska-Wynimko J. Bacterial immunostimulants -mechanism of action and clinical application in respiratory diseases. Pneumonol Alergol Pol 2008;76:353-359.

2 Zelle-Rieser C, Ramoner R, Bartsch G, Thurnher M. A clinically approved oral vaccine against pneumotropic bacteria induces the terminal maturation of CD83+ immunostimulatory dendritic cells. Immunol Lett 2001;76:63-67.

3 Emmerich B, Emslander HP, Pachmann K, Hallek M, Milatovic $\mathrm{D}$, Busch R. Local immunity in patients with chronic bronchitis and the effects of a bacterial extract, Broncho-Vaxom, on $\mathrm{T}$ lymphocytes, macrophages, gamma-interferon and secretory immunoglobulin $\mathrm{A}$ in bronchoalveolar lavage fluid and other variables. Respiration 1990;57:90-99.

4 Emmerich B, Pachmann K, Milatovic D, Emslander HP. Influence of $\mathrm{OM}-85-\mathrm{BV}$ on different humoral and cellular immune defense mechanisms of the respiratory tract. Respiration 1992;59 Suppl 3:19-23.

5 Schaad UB. Prevention of paediatric respiratory tract infections: emphasis on the role of OM-85. Eur Respir Rev 2005; 14:74-77.

6 Illi S, von Mutius E, Lau S, Bergmann R, Niggemann B, Sommerfeld C, et al. Early childhood infectious diseases and the development of asthma up to school age: a birth cohort study. BMJ 2001;322:390-395.

7 Pavia-Ruz N, Lopez P, Santos JI. Recurrent respiratory infection in children: its clinical and laboratory evaluation. Bol Med Hosp Infant Mex 1991;48:385-397.

8 von Mutius E, Illi S, Hirsch T, Leupold W, Keil U, Weiland SK. Frequency of infections and risk of asthma, atopy and airway hyperresponsiveness in children. Eur Respir J 1999;14:4-11.

9 Lina B, Valette M, Foray S, Luciani J, Stagnara J, See DM, et al. Surveillance of community-acquired viral infections due to respiratory viruses in Rhone-Alpes (France) during winter 1994 to 1995. J Clin Microbiol 1996;34:3007-3011.

10 Lopez-Yap A, Abdelnour A, Lomonte B, Porras O. Serum antibody response to polysaccharides in children with recurrent respiratory tract infections. Clin Diagn Lab Immunol 2001;8:1012-1014.

11 Schaad UB, Mutterlein R, Goffin H. Immunostimulation with 
OM-85-BV in children with recurrent infections of the upper respiratory tract: a double-blind, placebo-controlled multicenter study. Chest 2002;122:2042-2049.

12 Alho OP, Koivu M, Sorri M, Rantakallio P. Risk factors for recurrent acute otitis media and respiratory infection in infancy. Int J Pediatr Otorhinolaryngol 1990;19:151-161.

13 van Woensel JB, van Aalderen WM, Kimpen JL. Viral lower respiratory tract infection in infants and young children. BMJ 2003;327:36-40.

14 Del-Rio-Navarro BE, Gonzalez-Diaz S, Escalante-Dominguez AJ, Blandon-Vijil V. Immunostimulants in the prevention of respiratory infections. Int J Biotechnol 2007;9:246-260.

15 Collet JP, Boissel JP. OM-85 BV: primary versus secondary prevention. Respiration 1994;61 Suppl 1:20-23.

16 Higgins JPT, Green S, eds. Cochrane Handbook for Systematic Reviews of Interventions Version 5.0.1 [updated September 2008]. The Cochrane Collaboration, 2008. (Available from: www.cochrane-handbook.org)

17 Ahrens J, Wiedenbach M. Efficacy of the immunostimulant Broncho-Vaxom. Schweiz Med Wochenschr 1984;114:932-934.

18 Chen ZG, Ji JZ, Li M, Chen YF, Chen FH, Chen H. Immunoregulants improves the prognosis of infants with wheezing. Nan Fang Yi Ke Da Xue Xue Bao 2007;27: 1612-1613.

19 Collet JP, Ducruet T, Kramer MS, Haggerty J, Floret D, Chomel JJ, et al. Stimulation of nonspecific immunity to reduce the risk of recurrent infections in children attending day-care centers. The Epicreche Research Group. Pediatr Infect Dis J 1993;12:648-652.

20 Field J, Gómez-Barreto D, Del-Rio-Navarro BE, Berber A. Use of $\mathrm{OM}-85 \mathrm{BV}$ in the primary prevention of acute respiratory tract infections in children in orphanages. Cur Ther Res 1998;59:407-418.

21 Gutiérrez-Tarango MD, Berber A. Efficacy of a bacterial extract (OM-85 BV) in preventing recurrent respiratory tract infections in susceptible children. Clin Drug Investig 1997;13:76-84.

22 Kapellerova A, Sulko M, Krovinova A, Jakubovska M, Michalickova J, Mazarikova O. Immunologic indicators in the treatment of recurrent respiratory diseases using peroral bacterial vaccines. Cesk Pediatr 1989;44:454-458.

23 Maestroni GJ, Losa GA. Clinical and immunobiological effects of an orally administered bacterial extract. Int $\mathrm{J}$ Immunopharmacol 1984;6:111-117.

24 Martin du Pan RE, Martin du Pan RC. Clinical Study concerning the prevention of infections of the upper respiratory tract of preschool children. Schweiz Rundsch Med Prax 1982:71:1385-1389.

25 Quezada A, Maggi L, Perez MA, Rodriguez J. Effect of bacterial antigen lysate on $\operatorname{IgG}$ and IgA levels in children with recurrent infections and hypogammaglobulinemia. J Investig Allergol Clin Immunol 1999;9:178-182.

26 Ziuzio S, Sakson B. Vaccine therapy in the treatment of nasal and sinus bacterial allergies. Wiad Lek 1994;47:510-513.

27 Del-Rio-Navarro BE, Luis Sienra-Monge JJ, Berber A, TorresAlcántara S, Avila-Castañón L, Gómez-Barreto D. Use of OM-85 BV in children suffering from recurrent respiratory tract infections and subnormal IgG subclass levels. Allergol Immunopathol (Madr) 2003;31:7-13.

28 Gomez Barreto D, De la Torre C, Alvarez A, Faure A, Berber A. Safety and efficacy of OM-85-BV plus amoxicillin/clavulanate in the treatment of subacute sinusitis and the prevention of recurrent infections in children. Allergol Immunopathol (Madr) 1998;26:17-22

29 Gutiérrez-Tarango MD, Berber A. Safety and efficacy of two courses of OM-85 BV in the prevention of respiratory tract infections in children during 12 months. Chest 2001;119: $1742-1748$

30 Jara-Perez JV, Berber A. Primary prevention of acute respiratory tract infections in children using a bacterial immunostimulant: a double-masked, placebo-controlled clinical trial. Clin Ther 2000;22:748-759.

31 Paupe J. Immunotherapy with an oral bacterial extract (OM-85) for upper respiratory infections. Respiration 1991;58:150-154.

32 Schaad UB, Farine JC, Fux TH. Prospective placebo-controlled double-blind study using a bacterial lysate in infections of the respiratory tract and ENT region in children. Helv Paediatr Acta 1986;41:7-17.

33 Zagar S, Löfler-Badzek D. Broncho-Vaxom in children with rhinosinusitis: a double-blind clinical trial. ORL J Otorhinolaryngol Relat Spec 1988;50:397-404.

34 Jadad AR, Moore RA, Carroll D, Jenkinson C, Reynolds DJ, Gavaghan DJ, et al. Assessing the quality of reports of randomized clinical trials: is blinding necessary? Control Clin Trials 1996;17:1-12.

35 Bland M. An introduction to medical statistics. Oxford: Oxford Medical Publishing Ed., 1995: 235-238, 323-326.

36 Walfish S. A Review of Statistical Outlier Methods. Pharmaceutical Technology, 2006. http://pharmtech.findpharma. $\mathrm{com} /$ pharmtech/article/articleDetail.jsp?id= 384716 (accessed July 8, 2008).

37 Steurer-Stey C, Lagler L, Straub DA, Steurer J, Bachmann LM. Oral purified bacterial extracts in acute respiratory tract infections in childhood: a systematic quantitative review. Eur J Pediatr 2007;166:365-376.

38 De la Torre González C, Pacheco Ríos A, Escalante Domínguez AJ, del Río Navarro BE. Comparative meta-analysis of immunoestimulant agents used in pediatric patients in Mexico. Rev Alerg Mex 2005;52:25-38.

39 Del-Rio-Navarro BE, Espinosa Rosales F, Flenady V, SienraMonge JJL. Immunostimulants for preventing respiratory tract infection in children. Cochrane Database Syst Rev 2006;(4): CD004974.

40 Barden J, Derry S, McQuay H, Moore R. Bias from industry trial funding? A framework, a suggested approach, and a negative result. Pain 2006;121:207-218.

41 Bero L, Oostvogel F, Bacchetti P, Lee K. Factors associated with findings of published trials of drug-drug comparisons: why some statins appear more efficacious than others. PLoS Med 2007;4:e184.

42 Jørgensen AW, Hilden J, Gøtzsche PC. Cochrane reviews compared with industry supported meta-analyses and other meta-analyses of the same drugs: systematic review. BMJ 2006;333:782.

43 LeLorier J, Grégoire G, Benhaddad A, Lapierre J, Derderian F. Discrepancies between meta-analyses and subsequent large randomized, controlled trials. N Engl J Med 1997;337:536-542.

44 Ioannidis JP, Lau J. Evolution of treatment effects over time: empirical insight from recursive cumulative meta analyses. PNAS 2001;98:831-836.

Received November 21, 2008 Accepted after revision May 25, 2009 